\title{
Correlation of nerve conduction study parameters with thyroid hormone in newly diagnosed hypothyroid patients
}

\author{
Shital Gupta1, Rita Khadka², Dilip Thakur³, B. H. Paudel ${ }^{4}$, Robin Maskey5, K. D. Mehta ${ }^{6}$ \\ ${ }^{1}$ Assistant Professor, ${ }^{2}$ Additional Professor, ${ }^{3,4}$ Professor, Department of Basic and Clinical Physiology, ${ }^{5}$ Professor, \\ Department of Internal Medicine, ${ }^{6}$ Assistant Professor, Department of Biochemistry, B. P. Koirala Institute of Health \\ Science, Dharan, Nepal
}

Background: Thyroid hormones act on many organs including central and peripheral nervous system for maintaining metabolic homeostasis. Entrapment neuropathies are most common in hypothyroidism. Nerve conduction parameters are impaired even in newly diagnosed cases of hypothyroid. Aims and Objectives: This study aims to study the correlation between thyroid hormone and nerve conduction study (NCS) parameters in newly diagnosed hypothyroid patients. Materials and Methods: This cross-sectional, descriptive study included newly diagnosed hypothyroid patients ( $n=30$; age: $31.96 \pm 9.12$ ). In all subjects, NCS was performed in median, ulnar, tibial motor nerve and median, ulnar, sural sensory nerve using Nihon Kohden machine in Neurophysiology lab 2, B. P. Koirala Institute of Health Science. Thyroid function test (TFT) was analyzed by ELISA. The association between thyroid hormone and NCS parameters was done using Pearson's correlation. Results: In NCS sensory parameters; SNAP amplitude of the left sural nerve showed significant positive correlation with $\mathrm{t} 3(\mathrm{It} ; \mathrm{r}=0.451, \mathrm{P}=0.012)$. Among motor parameters, distal latency of left median nerve showed significant negative correlation with $\mathrm{t} 3$ whereas nerve conduction velocity of the left median nerve showed positive correlation with $\mathrm{t} 3$. In rest of the nerve, the association between NCS parameters and TFT (t3, t4, and TSH) parameters did not show any significant changes. Conclusion: Our study reveals that in newly diagnosed cases of hypothyroidism, nerve impairment occurs in which the left side is affected much earlier than right side and further its severity can be correlated with level of $\mathrm{T} 3$ rather than TSH.

Key words: Nerve conduction study; Thyroid function test; Thyroid-stimulating hormone

\section{Access this article online}

Website:

http://nepjol.info/index.php/AJMS DOI: 10.3126/ajms.v12i11.38955

E-ISSN: 2091-0576

P-ISSN: $2467-9100$

Copyright (c) 2021 Asian Journal of Medical Sciences

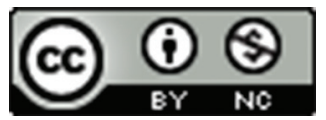

This work is licensed under a Creative Commons Attribution-NonCommercial 4.0 International License.

\section{INTRODUCTION}

The thyroid glands secrete thyroid hormones, that is, triiodothyronine (T3) and thyroxine (T4) which play an important role in tissue development and metabolism. ${ }^{1}$ Nervous system gets affected in thyroid disorder, leading to central or peripheral neuropathy. In hypothyroidism, types of neuropathies mostly seen are focal entrapment neuropathy, especially carpal tunnel syndrome and peripheral neuropathy. ${ }^{2}$ The severity of neuromuscular signs and symptoms is known to be related to the duration and degree of hormonal deficiency.
Several studies have evidence of polyneuropathy in hypothyroidism involving motor, sensory, and mixed nerves. ${ }^{3,4}$ Hence, it can be said that there must be some relationship of nerve conduction impairment with that of thyroid hormone level.

The relationship between nerve conduction study (NCS) parameters and thyroid hormones has not been studied so far in our part in hypothyroid. Hence, we wanted to study the relationship between NCS parameters and thyroid function test (TFT) parameters in newly diagnosed hypothyroid patients. 
Aims and objectives

This study aims to study the relationship between NCS parameters and TFT parameters in newly diagnosed hypothyroid patients.

\section{MATERIALS AND METHODS}

It was a cross-sectional, descriptive type of study conducted on 30 newly diagnosed cases of hypothyroid patients of age ranging between 18 and 45 years and 30 healthy subjects for control group of similar age group in the Department of Basic and Clinical Physiology, from July 2014 to June 2015 at BPKIHS, Dharan. Ethical approval was taken from the Institutional Review Committee and written informed consent was obtained from all participants.

Person with clinically diagnosed systemic illness such as hypertension, diabetes mellitus any cardiovascular, respiratory disease, neuromuscular disorder, smokers, alcoholic, or person on treatment of hypothyroidism were excluded from the study. TFT was assessed by ELISA. The detailed information regarding the study/procedure was explained to the subject. Proper history and clinical examination were taken. NCS was performed (median, ulnar, tibial, and sural nerve, bilaterally) in all subjects using standard pro forma.

Motor NCS of median, ulnar, and tibial nerves was recorded using Digital Nihon Kohden (NM_420S, H636, Japan) by belly tendon montage. Nerve conduction parameters recorded were latency, CMAP (compound motor action potential) amplitude, and nerve conduction velocity.

Sensory NCS of median, ulnar, and sural nerve was recorded using orthodromic method (median and ulnar nerve) and antidromic method (sural nerve) using ring electrodes. Nerve conduction parameters recorded were onset latency, sensory nerve action potential (SNAP) amplitude, and nerve conduction velocity.

The statistical analysis was done using SPSS (11.5 version). The association between TFT parameters and NCS parameters was done using Pearson's correlation and Spearman's correlation based on the distribution of data. $\mathrm{P}<0.05$ was considered as statistically significant.

\section{RESULTS}

On comparison of general characteristics between hypothyroid patients and control, no significant changes were found as previously stated in Table 1.5

\begin{tabular}{lcc}
\multirow{2}{*}{$\begin{array}{l}\text { Table 1: Correlation between sensory and motor } \\
\text { parameters of nerve conduction study and t3 in } \\
\text { hypothyroid patients } \\
\text { NCS parameters }\end{array}$} & \multicolumn{2}{c}{$\mathbf{t 3}$} \\
\cline { 2 - 3 } & $\mathbf{R}$ & $\mathbf{P}$ \\
\hline Sensory nerve & & 0.493 \\
LSL (ms) & -0.13 & $0.012^{*}$ \\
LSAMP (mv) & 0.451 & 0.636 \\
LSNCV (m/s) & 0.09 & 0.256 \\
RSL (ms) & -0.214 & 0.074 \\
RSAMP (mv) & 0.331 & 0.242 \\
RSNCV (m/s) & 0.22 & \\
Motor nerve & & $0.04^{*}$ \\
LMDL (ms) & -0.377 & 0.682 \\
LMAMP (mv) & 0.078 & $0.014^{*}$ \\
LMNCV (m/s) & 0.442 & 0.226 \\
RMDL (ms) & -0.228 & 0.583 \\
RMAMP (mv) & 0.104 & 0.365 \\
RMNCV (m/s) & 0.171 &
\end{tabular}

t3: Triiodothyronine, NCS: Nerve conduction study, LSL: Left sural onset latency, LSAMP: Left sural amplitude, LSNCV: Left sural nerve conduction velocity, RSL: Right sural onset latency, RSAMP: Right sural amplitude, RSNCV: Right sural nerve conduction velocity LMDL: Left median nerve distal latency, LMAMP: Left median nerve amplitude, LMNCV: Left median nerve conduction velocity, RMDL: Right median nerve distal latency, RMAMP: Right median nerve amplitude, RMNCV: Right median nerve conduction velocity

TFT parameters of hypothyroid patients were as follows: t3 (2.262 \pm 0.798$)$, t4 (1.370 (1.230-1.593), and thyroid-stimulating hormone (TSH) (36.512 \pm 16.853$)$, whereas that of healthy control were t3 $(2.961 \pm 0.979)$, T4 (2.475 (1.323-7.273). and TSH (2.584 \pm 0.626$)$. Value of t3 $(\mathrm{P}=0.004)$ and $\mathrm{t} 4(\mathrm{P}=0.001)$ was significantly lower in hypothyroid patients whereas TSH $(\mathrm{P}=0.001)$ was increased as compared to control.

In NCS sensory parameters, SNAP amplitude of the left sural nerve showed significant positive correlation with t3 (Table 1). Among motor parameters, distal latency of the left median nerve showed significant negative correlation with $\mathrm{t} 3$ whereas nerve conduction velocity of the left median nerve showed positive correlation with $\mathrm{t} 3$ (Table 1). In rest of the nerve, the association between NCS parameters and TFT ( $\mathrm{t} 3, \mathrm{t} 4$, and TSH) parameters did not show any significant changes.

\section{DISCUSSION}

We studied correlation between NCS parameters (median, ulnar, tibial, and sural nerve) and thyroid hormone parameters in newly diagnosed hypothyroid patients.

Among sensory parameters of NCS, SNAP amplitude of sural nerve on the left side showed significant positive correlation with $\mathrm{t} 3$; whereas onset latency and nerve conduction velocity and SNAP amplitude of the bilateral 
median and ulnar nerve did not show any significant correlation with $\mathrm{t} 3$.

The association between $\mathrm{t} 4$ and TSH with NCS parameters in terms of onset latency, distal latency, SNAP amplitude, CMAP amplitude, and nerve conduction velocity did not show any significant changes in median, ulnar, tibial, and sural nerve.

Findings are in contrast with Yeasmin et al. ${ }^{6}$ They found significant positive correlation of median sensory distal latency with TSH and significant negative correlation of latency of sural nerve with t4. We found significant changes with $\mathrm{t} 3$ and not with $\mathrm{t} 4$ and TSH may be because we have taken newly diagnosed case in which patients had not started medication whereas in study by Yeasmin et al., they had taken hypothyroid patient who was on medication. Hence, it may be that the treatment may have normalized the level of thyroid hormone. In our study, the left side is affected in early stage more than right, it may be due to the sensitivity of the hormones may vary differently on the right and left side. It needs to be further studied.

Among motor parameters of NCS, distal onset latency of the left median nerve showed significant negative correlation with t 3 whereas nerve conduction velocity of the left median nerve showed significant positive correlation with $\mathrm{t} 3$.

Findings are supported by Das et al. ${ }^{7}$ They found a significant negative correlation of median and ulnar distal latency with $\mathrm{t} 3$ whereas significant positive correlation of median and ulnar conduction velocity with $\mathrm{t} 3$. Though the subject studied were newly diagnosed subclinical hypothyroidism which is mild form of hypothyroidism. It may be due to deposition of glycosaminoglycans in nerves and soft tissue surrounding them may lead to degeneration of axons as well as myelin sheath.

Elevated TSH is not the marker of severity of the disease as TSH increases as a compensatory mechanism in hypothyroidism. Few studies suggest that level of TSH as a marker of brain hypothyroidism but not with peripheral neuronal activities. ${ }^{8}$ It means that nerve conduction parameters are affected earlier than the development of signs and symptoms. Our findings suggest that we can determine the impairment of neuronal activity by level of $t 3$ which is the active form of thyroid hormone rather than TSH.
Limitation of the study

We faced less limitation in our study.

\section{CONCLUSION}

Our study reveals that in newly diagnosed cases of hypothyroidism, nerve impairment occurs in which left side is affected much earlier than right side and further its severity can be correlated with level of $t 3$ rather than TSH which will further help in early management of cases.

\section{ACKNOWLEDGMENT}

I am highly indebted to all the subjects those who participated in my research. It would not have been possible to complete without them.

\section{REFERENCES}

1. Barett K, Brooks H, Boitano S, Barman S. The thyroid gland. In: Ganong's Review of Medical Physiology. United States: Tata MCGraw; 2012.

2. Duyff RF, Bosch J, Laman D and Linssen WH. Neuromuscular findings in thyroid dysfunction: A prospective clinical and electrodiagnostic study. J Neurol Neurosurg Psychiatry. 2000;68(6):750-755.

https://doi.org/10.1136/jnnp.68.6.750

3. Nemni R, Bottachi $E$ and Fazio R. Polyneuropathy in hypothyroidism: Clinical, electrophysiological and morphological findings in four cases. J Neurol Neurosurg Psychiatry. 1987;50(11):1454-1460.

https://doi.org/10.1136/jnnp.50.11.1454

4. Adikesavan B, Gowdhaman N, Rao V and Kabali B. A study of nerve conduction velocity in newly diagnosed hypothyroid females. World J Med Sci. 2013;9(4):198-201. Available from: https://www.idosi.org/wjms/9(4)13/3.pdf

5. Gupta S, Khadka R, Thakur D, Maskey R, Mehta KD and Paudel BH. Nerve conduction and heart rate variability in patients with hypothyroidism at a Tertiary Care Centre in eastern Nepal. J Nepal Med Assoc. 2017;56(208):407-411. https://doi.org/10.31729/jnma.3316

6. Yeasmin S, Begum N, Begum S and Rahman S. Relationships of nerve conduction parameters with the thyroid hormones in hypothyroid patients. J Bangladesh Soc Physiol. 2013;8(1):1-5. https://doi.org/10.3329/jbsp.v8i1.16638

7. Das P, Pradhan $P$ and Ghosal S. Assessment of peripheral neural activity with nerve conduction studies in subclinical hypothyroid females from rural area of Bankura district of West Bengal. Int J Biomed Res. 2017;8(11):605-608.

8. Schraml FV, Goslar PW, Baxter L and Beason-Held LL. Thyroid stimulating hormone and cognition during severe transient hypothyroidism. Neuro Endocrinol Lett. $2011 ; 32(3): 279-285$. 
Authors' Contributions:

SG- Concept, Coordination, statistical analysis, interpretation, manuscript preparation, and revision of manuscript; RK- Concept, Study design, interpretation,

and revision of manuscript; DT- Reviewed the literature and interpretation of results; BHP-Concept and revision of manuscript, RM- Manuscript preparation and interpretation of result, KDM- Reviewed literature and interpretation of results.

Work Attributed to:

B. P. Koirala Institute of Health Science, Dharan, Nepal.

ORCID ID:

Dr. Shital Gupta- (D) https://orcid.org/0000-0003-1281-9892

Dr. Rita khadka- (1) https://orcid.org/0000-0002-5627-8007

Dr. Dilip Thakur- 10 https://orcid.org/0000-0003-4183-5584

Prof. BH Paudel- (i) https://orcid.org/0000-0003-3655-6038

Dr. Robin Maskey- (iD https://orcid.org/0000-0001-8272-5141

Mr. KD Mehata- (1) https://orcid.org/0000-0002-1431-1833

Source of Funding: None, Conflicts of Interest: None. 